\title{
Role of DWI MRI as a Recent Modality in Differentiation between Benign from Malignant Ovarian Tumors
}

\author{
DAWLAT A. ABD EL-MAGEED, M.Sc.; NAGLAA SHEBREYA, M.D. and NERMEEN N. KERIAKOS, M.D. \\ The Department of Radiodiagnosis, Faculty of Medicine, Ain Shams University
}

\begin{abstract}
Background: Determining whether a clinically diagnosed adnexal mass is benign or malignant is frequently not possible until surgical exploration and histologic examination are performed. Consequently, it may not be possible to decide pre-operatively whether conservative or radical surgery is appropriate. Areliable method with which to differentiate a benign from a malignant adnexal mass would provide a basis for optimal pre-operative planning.
\end{abstract}

Aim of Study: To get judgment for the utilized MRI tools of assessment and to find out whether diffusion weighted imaging is a necessity or luxury in case we need to asses an adnexal mass.

Patients and Methods: The current study is a prospective analysis that was conducted at Ain Shams University Hospital and Damnhour Scan Center from 2018 to 2019. The study was performed on 22 cases of ovarian tumors. 5 patients presented by abdominal enlargement, 5 were complaining of long standing abdominal pain, 7 came with other different complaints; 4 came complaining with frequency of micturition, dysuria, loss of weight and one case accidentally discovered during US examination.

Results: DWI had shown $100 \%$ sensitivity in its individual performance; yet a low specificity which was $78.6 \%$. Such low specificity value was attributed to the presence of benign masses that have mimicked malignancy on DWI; starting from their misleading signal intensities of restricted diffusion, down to their measured ADC values. These masses were: Mature teratomas and tubo-ovarian abscess.

Conclusion: The solo performance of DWI is not an applicable way to discriminate benign from malignant adnexal masses due to its low specificity. According to us, DWI has sensitivity of $(100 \%)$, but didn't improve the specificity $(78.6 \%)$ or the accuracy (86.4\%). DWI can help and increase confidence of MRI in assessment or exclude potential malignancy in complex adnexal masses; provided I) inclusion of the conventional MRI data, II) Combined analysis of DWI quantitative and qualitative criteria and iii) awareness of the possible sequence pitfalls.

Key Words: Diffusion-weighted imaging - Malignant Ovarian Tumors - MRI.

Correspondence to: Dr. Dawlat A. Abd El-Mageed, E-Mail: dawletomer@yahoo.com

\section{Introduction}

ADNEXAL masses remain the first indication for gynecologic surgery. The objectives of the use of imaging techniques are to reduce the number of women unnecessarily undergoing cancer surgery, to preserve fertility in young women (by allowing laparoscopy), and, when necessary, to enable the referral of patients to a tertiary referral center with a specialist gynecologic oncologist to ensure optimal primary surgical treatment [1].

Determining whether a clinically diagnosed adnexal mass is benign or malignant is frequently not possible until surgical exploration and histologic examination are performed. Consequently, it may not be possible to decide preoperatively whether conservative or radical surgery is appropriate. A reliable method with which to differentiate a benign from a malignant adnexal mass would provide a basis for optimal preoperative planning and may also reduce the number of unnecessary laparotomies patients undergo for benign disease [2]

Ultrasonography (US) is the modality of choice for evaluation of adnexal masses, the primary disadvantage of ultrasonography (US) includes its limitation for characterization of the masses and staging for malignant masses [3].

Pelvic MRI is helpful in difficult cases and may provide a more definitive diagnosis. MRI is commonly utilized for evaluation of cystic or solid adnexal or ovarian masses in which ultrasound cannot be diagnostic or when there are worrisome or indeterminate ultrasound features. MRI may identify the location of the mass and determine if it is a cystic, solid, or complex. MRI has a high accuracy in differentiating benign from malignant masses. Teratomas, endometriomas, simple and hemorrhagic cysts, fibromas, exophytic or extrau- 
terine fibroids and hydrosalpinges can be diagnosed with high confidence [4].

DWI is a non-invasive modality that helps in discrimination between benign and malignant lesions, increase the contrast between lesions and surrounding tissues, and improve the detection and delineation of peritoneal implants at both initial staging and follow-up. Moreover, diffusion-weighted imaging provides quantitative information about tissue cellularity that may be used to distinguish viable tumors from treatment-related changes [5]. When diffusion-weighted MR imaging is used in gynecologic applications, areas charachterized by 'restricted' diffusion or by low values of the apparent diffusion coefficient generally correspond with foci of hypercellularity. Therefore, compatible with uncontrolled malignant proliferation. By performing DWI using different b-values, quantitative analysis, namely, the calculation of Apparent Diffusion Coefficient (ADC) values, is possible and the ADC values can be displayed as a parametric map (ADC map). Resticted water diffusion demonstrates high signal intensity on DWI and lower ADC values on ADC map [6]
(A)

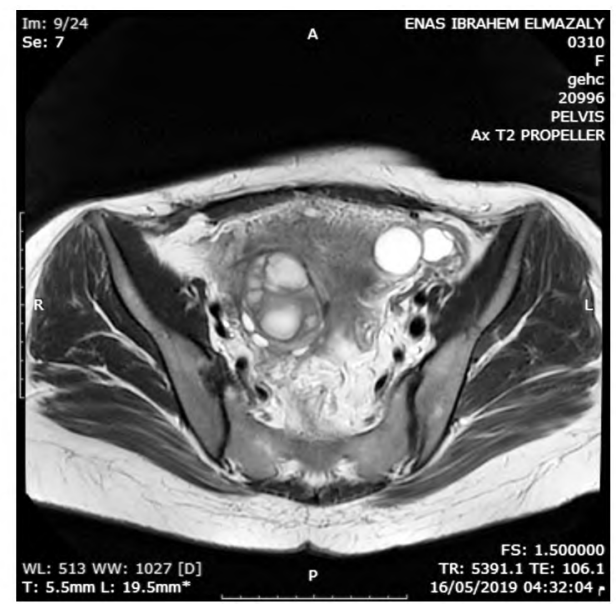

$\mathrm{T} 2$

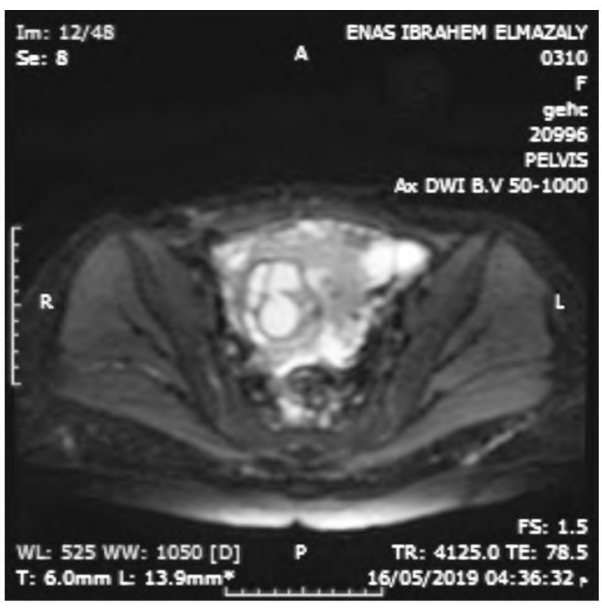

DWI

(B)

Fig. (1): Case of right tubo-ovarian absecc elicit bright signal in T2 image (A) and showed high signal on DWI (B) with low signal on the corresponding ADC maps ADC value of the tumor was $1.74 \pm 0 \times 10^{3} \mathrm{~mm}^{2} / \mathrm{s}$.

(A)

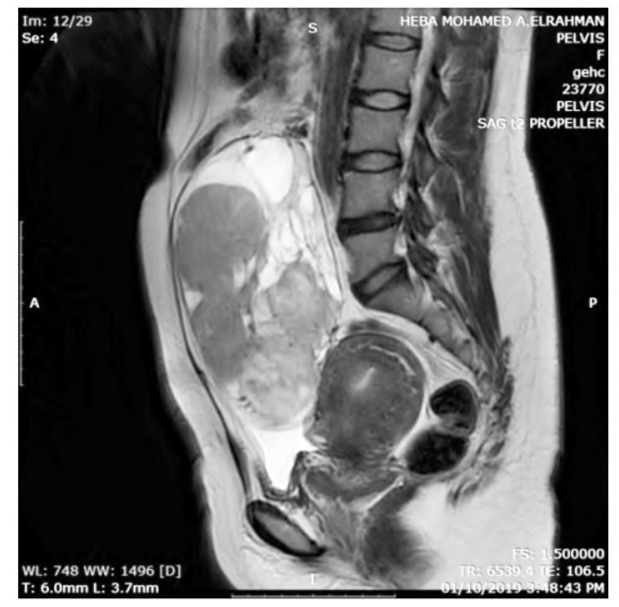

$\mathrm{T} 2$

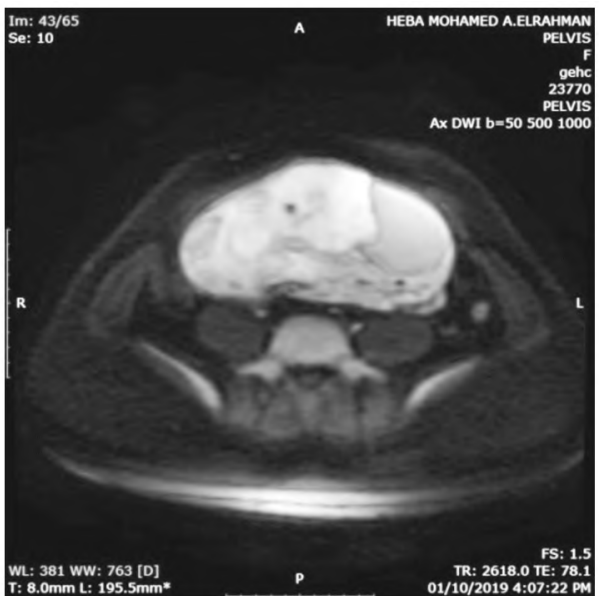

DWI

Fig. (2): Case of serous cystadenocarcinoma shows bright signal in T2 (A) and persistent high signal on DWI (B) with intermediate signal on the corresponding ADC maps of the solid component. ADC value of the solid portion of the tumor $0.9 \pm 0 \times 10^{-3} \mathrm{~mm}^{2} / \mathrm{s}$. 


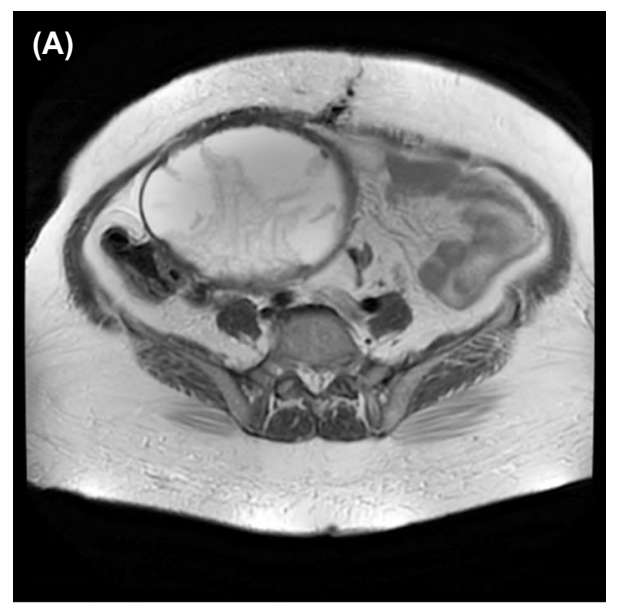

$\mathrm{T} 2$

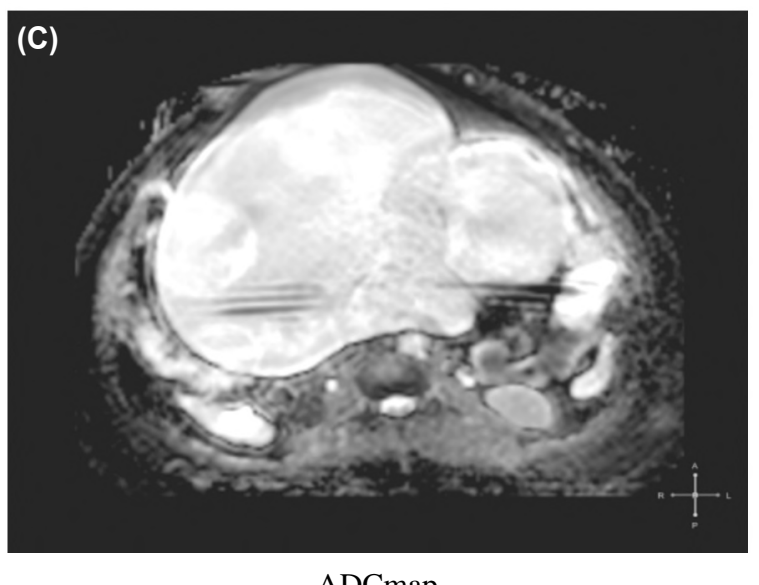

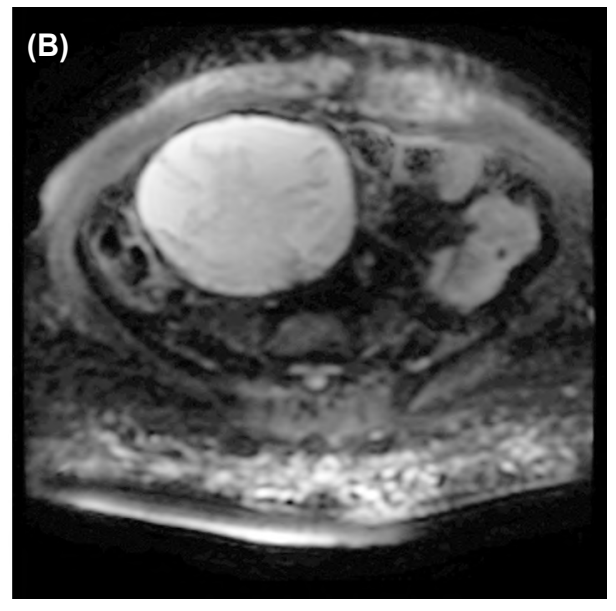

DWI

Fig. (3): Case of right mucinous cystadenoma shows high on T2-WI (A) and $\mathrm{AD}_{2} \mathrm{C}$ value of the tumor was $2.41 \pm 0.56 \times 10^{-3} \mathrm{~mm} / \mathrm{s}$ $( \pm$ SD 44.4). Low signal on DWI (B) with high signal on the corresponding ADC maps (C).

Aim of the study:

To determine whether the addition of DW sequences to the routine MR imaging protocol can improve the diagnostic accuracy of complex adnexal masses (benign or malignant). Investigate the use of DWI in the detection of peritoneal implants at both initial staging and follow-up. DWI provides quantitative information about tissue cellularity, so the current study may be used in follow-up of cases with borderline and invasive malignant ovarian tumors to detect recurrence in the tumor and distinguish viable tumors from post therapy. Evaluate the ability DW images in accurate detection of pelvic lymph nodes in patients with ovarian gynecologic malignancy. DWI is a non-invasive cost effective sequence for evaluating diseases of the female pelvis.

\section{Patients and Methods}

The current study is a prospective analysis that was conducted at Ain Shams University Hospital and Damnhour Scan Center. The study was performed on 22 cases of ovarian tumors. 5 patients presented by abdominal enlargement, 5 were complaining of long standing abdominal pain, 7 came with other different complaints; 4 came complaining with frequency of micturition, dysuria, loss of weight and one case accidentally discovered during US examination.

All cases had been subjected to the following: Full history taking with a special emphasis on: Age, parity, age of menarche, time of menopause, past history of gynecological troubles or operations, and positive family history of gynecological malignancy. Routine laboratory investigation for all patients including: $\mathrm{CBC}$, random blood sugar, liver functions and kidney functions. US examination: All patients had undergone preliminary pelvic ultrasound examination to exclude pure cystic lesions. The examination was done on ultrasound machine GE logic 7, trans-abdominal and transvaginal ultrasound approaches was done using 3$4 \mathrm{MHz}$ and $7-8 \mathrm{MHz}$ probes respectively. Color Doppler was superimposed on masses to detect vascularity.

\section{MR imaging:}

MR imaging was performed on two devices (Philips Acheiva-Medicalsystem, Netherlands) system and GE explorer using a 1.5-T Explorer). 
All the patients were imaged in the supine position with the aid of pelvic phased-array coil.

\section{Patient preparation:}

Patients were instructed to fast for 3 hours and void urine 2 hours prior examination. Intravenous administration of $10 \mathrm{mg}$ of an antispasmodic drug was given immediately before MR imaging to reduce bowel peristalsis.

MR imaging protocol (Table 1):

Table (1): The sequences used in the study.

\begin{tabular}{|c|c|c|c|c|c|}
\hline Sequence & $\begin{array}{c}\text { TR } \\
\text { (msec.) }\end{array}$ & $\begin{array}{c}\mathrm{TE} \\
(\mathrm{msec} .)\end{array}$ & $\begin{array}{l}\text { FOV } \\
(\mathrm{mm})\end{array}$ & Matrix & $\begin{array}{l}\text { Slice } \\
\text { thickness } \\
(\mathrm{mm})\end{array}$ \\
\hline - T2 sagittal & 4000 & 400 & 36 & $256 \times 224$ & 4 \\
\hline - T2 axial & 4000 & 400 & 30 & $256 \times 224$ & 4 \\
\hline - $\mathrm{T} 1$ axial & 500 & 20 & 30 & $256 \times 224$ & 4 \\
\hline $\begin{array}{l}\text { - Fat suppression } \\
\text { (T1 axial) }\end{array}$ & 500 & 20 & 30 & $256 \times 224$ & 4 \\
\hline - $\mathrm{T} 2$ coronal & 4000 & 400 & $\begin{array}{l}300 X \\
300\end{array}$ & $256 \times 224$ & 4 \\
\hline $\begin{array}{l}\cdot \text { DWI (b 0, 500, } \\
1000)\end{array}$ & 7000 & 80 & 36 & & 5 \\
\hline
\end{tabular}

Slice gap is $0.5 \mathrm{~mm}$ and flip angle 160 in TI and $\mathrm{T} 2$ in diffusion gradient 30 .

\section{$M R$ imaging analysis:}

MR images were analyzed for the following: MR appearance of the tumor; whether cystic, solid or mixed, involvement of one or both ovaries, Signal intensity of the tumor, presence of vegetations, presence of ascites, presence of infiltrated pelvic or para aortic lymph nodes, involvement of other pelvic organs, presence of peritoneal and omental deposit.

According to signal characteristics Important for characterizing benign masses: Cystic tumors show low signal intensity in T1-weighted images and high signal intensity on T2-weighted images. Complex benign looking masses: High signal intensity on T $1 \mathrm{WI}$ is considered either fat or blood. On fat suppressed images low signal is noted with fat while high signal is still noted in blood. Solid tumor with very low signal intensity in T2WI is characteristic to fibrous tumor (e.g. ovarian fibroma).

\section{Interpretation of DWI:}

\section{Qualitative analysis:}

DW images were inspected for the presence of persistent high SI (restricted diffusion) in correlation to the solid components of the included masses on different $b$-values $(0,500,1000)$. Regarding suspicious lymph nodes and peritoneal deposits especially in presence of ascites, we searched for lesions (on peritoneal surfaces or at sites of lymph node deposits) with restricted diffusion, i.e. high signal on DWI similar to that seen in malignant tumors. All imaging results were compared with the histo-pathological diagnosis after surgery.

\section{Quantitative analysis:}

Regarding the quantitative analysis of DWI, we generated the ADC maps from the DWI from b-values $(0,500$ and 1000), then we selected the ROI manually on the largest possible area of the solid and the cystic component of the tumors, which was then automatically calculated on the work station to get the different ADC values.

\section{Statistical analysis:}

Computer software package SPSS was used in the analysis. For quantitative variables, mean (as a measure of central tendency) and standard deviation (as measures of variability) were presented. Frequency and percentages were presented for qualitative variables, sensitivity, specificity, PPV, NPV and accuracy all were calculated for the conventional MRI and for the DWI. $t$-test was used to estimate differences in quantitative variables.

\section{Results}

This study was conducted on 22 female patients ranging from 21 to 53 years old; most of lesions were on the right side (45.5\%), about $59.1 \%$ were mixed solid and cystic in composition, with more than half of them showed bright $\mathrm{T} 2$ signal (Table 2).

Table (2): Distribution of the cases according to age, bilaterality, composition and $\mathrm{T} 2$ intensity.

\begin{tabular}{|c|c|c|}
\hline & & Total no. $=22$ \\
\hline \multirow[t]{2}{*}{ Age: } & Mean $\pm \mathrm{SD}$ & $39.77 \pm 9.24$ \\
\hline & Range & $21-53$ \\
\hline \multirow[t]{3}{*}{ Bilaterally: } & Right & $10(45.5 \%)$ \\
\hline & Left & $7 \quad(31.8 \%)$ \\
\hline & Bilateral & $5 \quad(22.7 \%)$ \\
\hline \multirow[t]{3}{*}{ Composition: } & : Solid & $3 \quad(13.6 \%)$ \\
\hline & Cystic & $6 \quad(27.3 \%)$ \\
\hline & Mixed & $13(59.1 \%)$ \\
\hline \multirow[t]{3}{*}{ T2 intensity: } & Bright & $12(54.5 \%)$ \\
\hline & Low & $8 \quad(36.4 \%)$ \\
\hline & Intermediate & $2(9.1 \%)$ \\
\hline
\end{tabular}


DWI and ADC values of both solid and cystic components were calculated on all lesions. Mean and range of ADC values of both components is illustrated on (Table 3 ).

Table (3): DWI and ADC values of the studied lesions.

\begin{tabular}{clc}
\hline & Total no. $=22$ \\
\hline DWI: & Non restricted & $11(50.0 \%)$ \\
& Restricted & $11(50.0 \%)$ \\
Cystic: $:$ Mean \pm SD & $2.41 \pm 0.56$ \\
Range & $1.2-3.22$ \\
Solid: Mean \pm SD & $1.63 \pm 0.91$ \\
Range & $0.68-3.08$ \\
\hline
\end{tabular}

All cases were subjected to tissue diagnosis and the final results as shown on (Table 4) showed the 14 cases were diagnosed as benign lesion and 8 cases were malignant.

Table (4): Histopathological results of the different lesions.

\begin{tabular}{ll}
\hline & Total no.=22 \\
\hline Diagnosis: Mature cystic teratoma & $3(13.6 \%)$ \\
Simple cyst & $3(13.6 \%)$ \\
Mucinous cystadenoma & $2(9.1 \%)$ \\
Hemorrahgic cyst & $2(9.1 \%)$ \\
Fibrothecoma & $1(4.5 \%)$ \\
Tubo-ovarian abscess & $1(4.5 \%)$ \\
Fibroma & $1(4.5 \%)$ \\
Serous cystadenoma & $1(4.5 \%)$ \\
Papillary serous carcinoma & $2(9.1 \%)$ \\
Granulosa cell tumor & $2(9.1 \%)$ \\
Mucinous cystadenocarcinoma & $2(9.1 \%)$ \\
Serous cystadenocarcinoma & $1(4.5 \%)$ \\
Borderline papillary serous cystadenoma & $1(4.5 \%)$ \\
Benign & $14(63.6 \%)$ \\
Malignant & $8(36.4 \%)$ \\
\hline
\end{tabular}

There was no significant statistical correlation between risk of malignancy and the age of patient, lesion site, composition or its T2 signal intensity (Table 5).

As regarding the ADC value results showed that the malignant lesions have lower ADC value within the solid component than the benign lesions (Table 6).

There was high significant statistical correlation between the diffusion pattern of the lesion as well as the solid component ADC value and the risk of malignancy as shown in (Table 7).
Table (5): Association between patient age and lesions site, composition and $\mathrm{T} 2$ intensity and risk of malignancy.

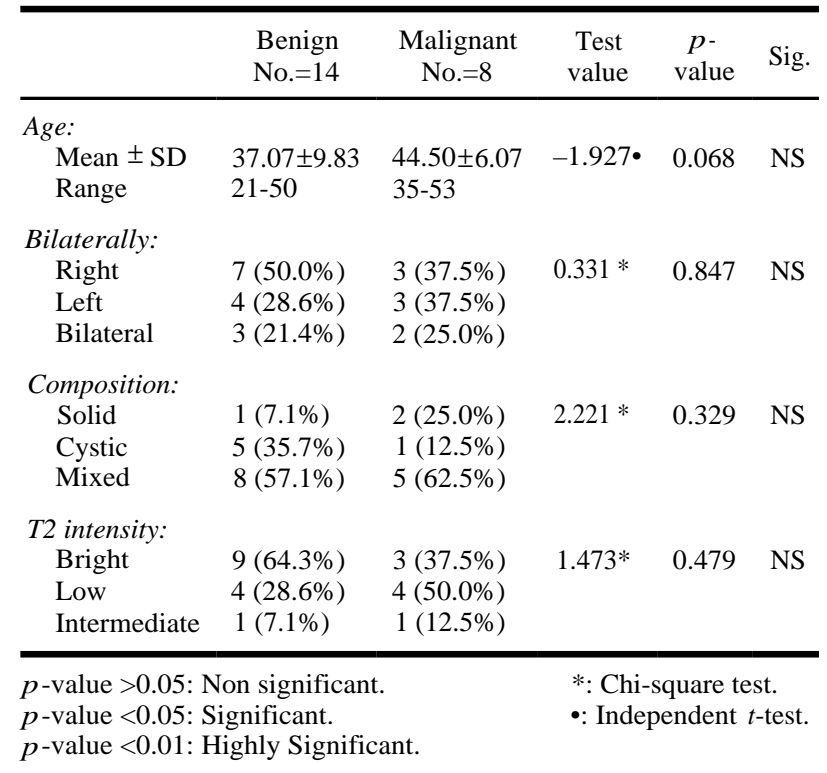

Table (6): Mean and SD of ADC value of the examined lesions.

\begin{tabular}{|c|c|c|}
\hline & $\begin{array}{c}\text { Cystic } \\
\text { Mean } \pm \text { SD }\end{array}$ & $\begin{array}{c}\text { Solid } \\
\text { Mean } \pm \text { SD }\end{array}$ \\
\hline \multicolumn{3}{|l|}{ Diagnosis: } \\
\hline Mature cystic teratoma & $2.83 \pm 0.33$ & $2.83 \pm 0.33$ \\
\hline Simple cyst & $2.7 \pm 0$ & $2.7 \pm 0$ \\
\hline Mucinous cystadenoma & $2.1 \pm 0.99$ & $2.1 \pm 0.99$ \\
\hline Hemorrahgic cyst & $2.49 \pm 0.43$ & $2.49 \pm 0.43$ \\
\hline Fibrothecoma & $1.95 \pm 0$ & $1.95 \pm 0$ \\
\hline $\begin{array}{l}\text { Tubo-ovarian abscess } \\
\text { Fibroma }\end{array}$ & $1.93 \pm 0$ & $1.93 \pm 0$ \\
\hline Serous cystadenoma & $3.1 \pm 0$ & $3.1 \pm 0$ \\
\hline Papillary serous carcinoma & & \\
\hline Granulosa cell tumor & $1.9 \pm 0.13$ & $1.9 \pm 0.13$ \\
\hline Mucinous cystadenocarcinoma & $2.55 \pm 0.07$ & $2.55 \pm 0.07$ \\
\hline Serous cystadenocarcinoma & $3 \pm 0$ & $3 \pm 0$ \\
\hline Borderline papillary serous cystadenoma & $1.2 \pm 0$ & $1.2 \pm 0$ \\
\hline \multicolumn{3}{|l|}{ Outcome: } \\
\hline Benign & $2.52 \pm 0.51$ & $2.52 \pm 0.51$ \\
\hline Malignant & $2.18 \pm 0.65$ & $2.18 \pm 0.65$ \\
\hline
\end{tabular}

Table (7): Association between diffusion pattern and solid component ADC value and risk of malignancy.

\begin{tabular}{|c|c|c|c|c|c|}
\hline & $\begin{array}{l}\text { Benign } \\
\text { No. }=14\end{array}$ & $\begin{array}{c}\text { Malignant } \\
\text { No. }=8\end{array}$ & $\begin{array}{c}\text { Test } \\
\text { value }\end{array}$ & $\begin{array}{c}p- \\
\text { value }\end{array}$ & Sig. \\
\hline \multicolumn{6}{|l|}{ DWI: } \\
\hline Non restricted & $11(78.6 \%)$ & $0(0.0 \%)$ & $12.571 *$ & 0.000 & HS \\
\hline Restricted & $3 \quad(21.4 \%)$ & $8(100.0 \%)$ & & & \\
\hline \multicolumn{6}{|l|}{ Cystic: } \\
\hline Mean $\pm \mathrm{SD}$ & $2.52 \pm 0.51$ & $2.18 \pm 0.65$ & $1.227 \bullet$ & 0.237 & NS \\
\hline Range & $1.4-3.22$ & $1.2-3$ & & & \\
\hline \multicolumn{6}{|l|}{ Solid: } \\
\hline Mean $\pm \mathrm{SD}$ & $2.19 \pm 0.79$ & $0.82 \pm 0.10$ & $4.472 \bullet$ & 0.000 & HS \\
\hline Range & $1.19-3.08$ & $0.68-0.96$ & & & \\
\hline \multicolumn{3}{|c|}{$\begin{array}{l}p \text {-value }>0.05 \text { : Non significant. } \\
p \text {-value }<0.05 \text { : Significant. } \\
p \text {-value }<0.01 \text { : Highly Significa }\end{array}$} & $\begin{array}{l}*: \text { Ch } \\
\bullet: \text { Ind }\end{array}$ & $\begin{array}{l}\text { quare } \\
\text { enden }\end{array}$ & $\begin{array}{l}\text { st. } \\
\text {-test. }\end{array}$ \\
\hline
\end{tabular}


Table (8): Showing statistical results of DWI in differentiating between benign and malignant lesions.

\begin{tabular}{rrrrrrrr}
\hline TP TN FP & $\begin{array}{r}\text { FN Sensi- } \\
\text { tivity }\end{array}$ & $\begin{array}{c}\text { Speci- } \\
\text { ficity }\end{array}$ & PPV & NPV & Accuracy \\
\hline DWI 8 & $\mathbf{1} 1 \mathbf{3}$ O & $100 \%$ & $78.6 \%$ & $72.7 \%$ & $100.0 \%$ & 0.864 \\
\hline
\end{tabular}

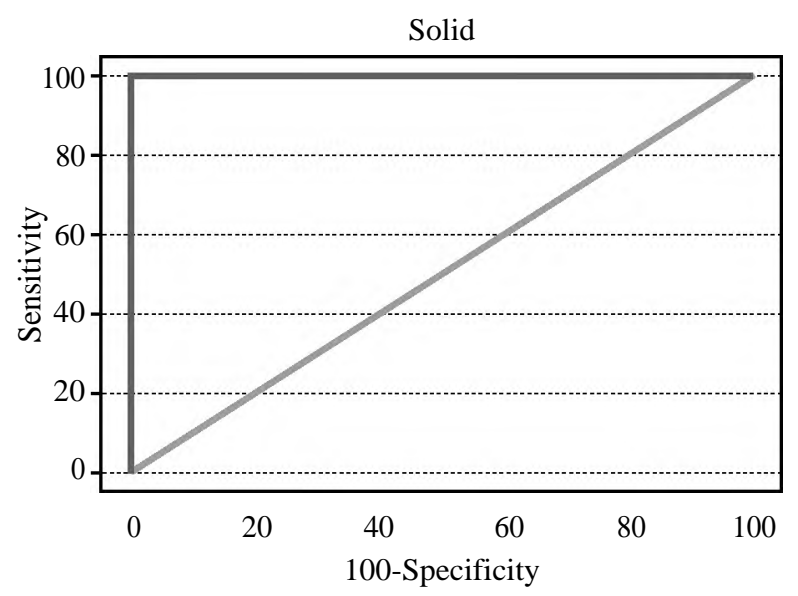

Fig. (4): ROC curve of the ADC value.

Table (9): Showing ROC results of ADC in differentiating between benign and malignant lesions.

\begin{tabular}{lccccc}
\hline Cut off point & AUC & Sensitivity & Specificity & + PV & $-P V$ \\
\hline$\leq 0.96$ & 1.000 & 100.00 & 100.00 & 100.0 & 100.0 \\
\hline
\end{tabular}

Receiver operating characteristic curve for solid in differentiation between benign and malignant cases.

*NPV: Negative Predictive Value.

*PPV: Positive Predictive Value.

\section{Discussion}

In our study, we included 22 patients with different ovarian lesions with mean age 39.7 years we focused on the evaluation of the role of diffusion MRI in differentiating between benign and malignant ovarian lesions.

In our study, we found that lesions in the right side were more than left side $(45.5 \%, 31.8 \%$ respectively) and $22.7 \%$ were bilateral lesions this was in agreement with Amir [7] study which had $62.5 \%$ of the lesions on the right side and $37.5 \%$ on the left side.

$25 \%$ of our malignant cases were solid, $62.5 \%$ and $12,5 \%$ were cystic this was close to the study done by Amir [7] in which malignant cystic lesions presented $12.5 \%$ and $81.25 \%$ of malignant cases were mixed cystic and solid,wih only pure solid case in this study $(6 \%)$.

In a study done by Zhang et al., [8] found that $52.7 \%$ of studied benign lesions (39/74) showing high signal in T2 weighted images and $84.3 \%$ of studied malignant lesions (108/128) showing high signal in T2 weighted images. This was different from our study which showed that $64.3 \%$ of benign cases had signal in T2 weighted images and only $37.5 \%$ of malignant lesions had signal in $\mathrm{T} 2$ weighted images.

In our study, $100 \%$ of malignant lesions in the study (8 malignant lesions) showed restricted diffusion with low ADC values. This agrees with Rajasri et al., [9] study which was carried on 112 female patients with initial undetermined complex adnexal masses referred for MRI based on ultrasound findings for further characterization and staging, they concluded that an adnexal mass with restricted diffusion usually is a malignant lesion. This finding, that of high signal intensity on DWI in solid components, may result from a reduction in both the extracellular matrix and the diffusion space of water protons in the extracellular and intracellular dimensions due to an increased nuclear to cytoplasmic ratio and hypercellularity.

In our study, we had 14 pathologically proven benign ovarian lesions, 11 cases showed facilitated diffusion and 3 cases showed restricted diffusion. This was in agreement with Nasr et al., [10] study which was conducted on 30 cases of different ovarian lesions, 12 cases were pathologically proved to be benign and 11 malignant), 7 of which only showed facilitated diffusion.

In our study, we had one case of tubo-ovarian abscesses with restricted diffusion. This was in agreement with Wang [11] study which carried on 34 cases of tubo-ovarian abscesses, all of which showed markedly homogeneous or heterogeneous hyper-intensity in the cystic component on DW images, indicating restricted water diffusion.

The mean ADC value of the cystic component in our study did not differ significantly between benign and malignant masses $(p=0.0 .237)$ as it was $2.52 \times 10^{-3} \pm 0_{-3} 5110^{-3} \mathrm{~mm}_{-3} / \mathrm{s}_{2}$ for benign tumors, $_{2}$ and $2.18 \times 10^{-3} \pm 0.65 \times 10^{-3} \mathrm{~mm}^{2} / \mathrm{s}$ for malignant tumors $\mathrm{w}$ this was considered statistically insignificant. This was close to the study done by $\mathrm{Li}$ et al., [12] which concluded that the mean ADC value of the cystic component was $2.58 \times 10^{-3} \pm 0.27 \mathrm{X}$ $10^{-3} \mathrm{~mm} / \mathrm{s}$ for benign tumors, and $2.44 \times 10^{-3} \pm$ $0.33 \times 10^{-3} \mathrm{~mm} / \mathrm{s}$ for malignant tumors which was also statistically insignificant.

On the other hand, we found the mean ADC value of the solid component can differs significantly between benign and malignant masses 
$(p<0.001)$ as it was $2.19 \times 10^{-3}+0.7910^{-3} \mathrm{~mm}_{2}^{2} / \mathrm{s}$ for benign tumors, and $0.82 \times 10^{-3} \pm 0.110^{-3} \mathrm{~mm} / \mathrm{s}$ for malignant tumors which also considered statistically significant. This also agree with Lie [12] who concluded that DWI is beneficial for differentiating between benign and malignant ovarian lesions regarding the solid components as they found that the mean $\mathrm{ADC}_{-3}$ value of the solid $_{2} \mathrm{com}$ ponent to be $1.69 \times 10^{-3} \pm 0.25 \times 10^{-3} \mathrm{~mm}^{2} / \mathrm{s}$ for benign tumors, and $1.03 \times 10^{-3} \pm 0.22 \times 10^{-3} \mathrm{~mm}^{2} / \mathrm{s}$ for malignant tumors which found to be statistically significant.

In our study, the sensitivity, specificity, PPV, NPV and accuracy of DWI imaging was all have $100 \%, 78.6 \%, 72.7 \%, 100 \%, 86.4 \%$ respectively according to ADC values of the solid components. This was in agreement with Li et al., [12] study which concluded that the sensitivity, specificity, PPV, NPV and accuracy of conventional MR imaging all have increased after adding DWI to the conventional MRI.

In our study, wefound that $\mathrm{ADC}$ value $\leq 0.96 \mathrm{X}$ $10^{-3} \mathrm{~mm} / \mathrm{s}$ is the optimal cutoff for differentiating between benign and malignant tumors with sensitivity of $100 \%$, specificity of $78.6 \%$, PPV of $72.7 \%$, NPV of $100 \%$ and accuracy of $86.4 \%$ this was close to Khaled and Ahmed [13] study carried on 20 female patients with different ovarian lesions underwent Diffusion-Weighted (DW) Magnetic Resonance (MR) aiming to evaluate the role of DWI in differentiating between benign and malignant ovarian lessions, they concluded that ADC value $0.9 \times 10^{-3} \mathrm{~mm} / \mathrm{s}$ may be the optimal cutoff for differentiating between benign and malignant tumors with specificity of $100 \%$, sensitivity of $88.9 \%$, NPV of $75 \%$, PPV of $100 \%$ and accuracy of $91.7 \%$.

\section{Conclusion:}

The solo performance of DWI is not an applicable way to discriminate benign from malignant adnexal masses due to its low specificity. According to us, DWI has sensitivity of $(100 \%)$, but didn't improve the specificity (78.6\%) or the accuracy $(86.4 \%)$. DWI can help and increase confidence of MRI in assessment or exclude potential malignancy in complex adnexal masses; provided I) Inclusion of the conventional MRI data, II) Combined analysis of DWI quantitative and qualitative criteria and III) Awareness of the possible sequence pitfalls.

\section{References}

1- THOMAS SIN-NAGGARA I., AUBERT E., ROCKALL A., JALAGUIER-COUDARY A., ROUZIER R., DARAI E., et al.: Adnexal Masses: Development and preliminary Validation of an MR Imaging Scoring System, 267 (2): 432-43, 2013.

2- SOHAIB S.A.A., SAHDEV A., TRAPPEN P.V., JACOBS I.J. and REZNEK R.H.: Characterization of adnexal mass lesions on MR imaging, 180 (5): 1297-304, 2003.

3- ZHANG H., ZHANG G.F., HE Z.Y., LI Z.Y. and ZHANG G.X.: Prospective evaluation of 3T MRI findings for Primary Adnexal Lesions and Comparison with final histological diagnosis, 289: 357-64, 2014.

4- RAJKOTIA K., VEERAMANI M. and MACURA K.J.: Magnetic Resonance Imaging of Adnexal Masses, 17 (6): 379, 2006

5- KYRIAZI S., KAYE S. and M. DESOUZA N.: Imaging ovarian cancer and peritoneal metastases, current and emerging techniques Clin. Oncol., 7: 381-93, 2010.

6- MOTOSHIMA S., IRIE H., NAKAZONO T., KAMURA T. and KUDO S.: Diffusion-weighted MR imaging in gynecologic cancers. J. Gynecol. Oncol., 22 (4): 275-87, 2011.

7- AMIR D.H., KAMBADAKONE A., HOLALKERE N.S., GUIMARAES A.R., HAHN P.F. and LEE S.I.: Diffusion MRI of uterine and ovarian masses: Identifying the benign lesions. Abdominal Radiology, 41 (12): 2466-75, 2016.

8- ZHANG P., CUI P., LI W., REN G., CHU C. and WU X.: Diagnostic accuracy of diffusion-weighted imaging with conventional MR imaging for differentiating complex solid and cystic ovarian tumors at 1.5T, Zhang et al., World Journal of Surgical Oncology, 10: 237, 2012.

9- RAJASRI B., PRASAD H. and SREE S.: Role of diffusion weighted MR imaging in adnexal lesions in female pelvis a prospective study. JMSCR, 4: 12675-85, 2016.

10- NASR I., HAMED I., ABBAS I. and KHALIFA N.M.: Dynamic contrast enhanced MRI in correlation with diffusion weighted (DWI) MR for characterization of ovarian masses, The Egyptian Journal Of Radiology And Nuclear Medicine, 45 (3): 975-85, 2014.

11- WANG T., LI W., WU X., YIN B., CHU C., DING M and CUI Y.: Tubo-ovarian abscess (with/without pseudotumor area) mimicking ovarian malignancy: Role of diffusion-weighted MR imaging with apparent diffusion coefficient values. PloS one, 11 (2), 2016.

12- LI X.R., CHENG L.Q., LIU M., ZHANG Y.J., WANG J.D., ZHANG A.L., SONG X., LI J., ZHENG Y.Q. and LIU L.: DW-MRI ADC values can predict treatment response in patients with locally advanced breast cancer undergoing neoadjuvant chemotherapy. Medical oncology, 29 (2): 425-31, 2012.

13- KHALED K.A. and AHMED A.: The significance of added ADC value to conventional MR imaging in differentiation between benign and malignant ovarian neoplasms. The Egyptian Journal of Radiology and Nuclear Medicine, 45 (3): 997-1002, 2014. 


\section{دور آشعة الرنين المغناطيسى فى التفرقة بين المبين

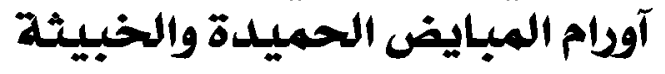

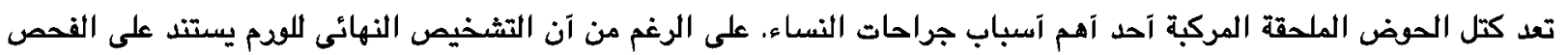

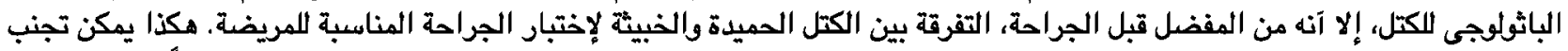

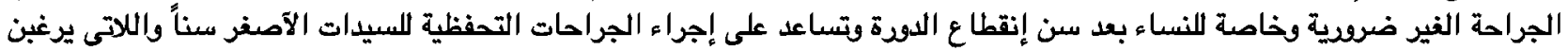
فى المحافظة على القدرة على الإنجاب.

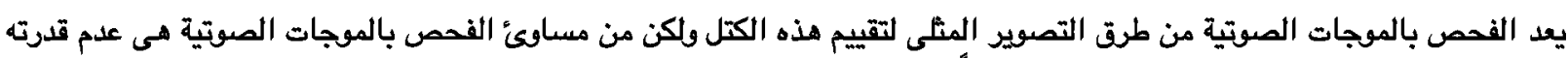

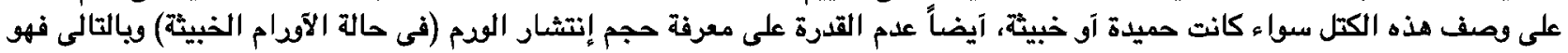

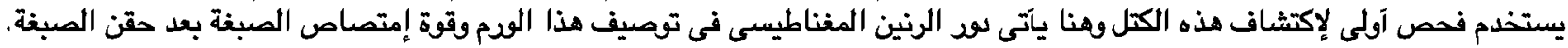

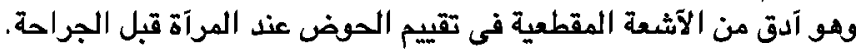

مع تطود التقنيات الحديثة فى التشخيص، تم إستحداث تقنيات جديدة للتصوير الوظيفى، منها الرنين المغناطيسى بالإنتشار الجزيئى والرنين المغناطيسى متعدد المراحل. 